\title{
Recycling Waste Electrical Socket as a Carbon Resource in Ironmaking*
}

\author{
J. R. Dankwah, E. Abotar, J. J. K. Gordon and P. Koshy
}

Dankwah, J. R., Abotar, E., Gordon, J. J. K, and Koshy, P. (2016), "Recycling Waste Electrical Socket as a Carbon Resource in Ironmaking”, Ghana Mining Journal, Vol. 16, No. 1, pp. 76 - 82.

\begin{abstract}
Globally, millions of waste electrical sockets (WES) are generated annually. This category of waste material is difficult to recycle because they are thermosetting polymers which cannot be remoulded after setting. In this work, the reduction of medium grade Agbaja iron ore from Nigeria, by carbonaceous materials generated from WES was investigated through experiments conducted in a domestic microwave oven. Composite pellets of medium grade Agbaja iron ore (assaying 74 \% $\mathrm{Fe}_{2} \mathrm{O}_{3}$ ) with WES were irradiated in a domestic microwave oven (Pioneer, Model PM-25 L, $2450 \mathrm{MHz}$ and $1000 \mathrm{~W}$ ). The reduced mass was characterised by XRD and $\mathrm{SEM} / \mathrm{EDS}$ analyses and the extent of reduction after $40 \mathrm{~min}$ was determined. SEM/EDS analysis revealed a highly reduced mass with distinct peaks of elemental iron and this was corroborated by XRD analyses that confirmed the formation of metallic iron. The extent of reduction obtained after using WES as reductant was over $80 \%$. Accordingly, carbonaceous materials generated from waste electrical sockets are effective reductants for producing metallic iron from the Agbaja iron ore.
\end{abstract}

Keywords: Waste Electrical Sockets, Thermosetting Polymer, Agbaja Iron Ore; Municipal Solid Waste

\section{Introduction}

Globally, millions of waste electrical sockets (WES) are generated annually. This category of waste is difficult to recycle because they are produced from thermosetting polymers which cannot be remoulded after setting. As a result, incineration at landfills sites is the major mode for destruction of WES. Unfortunately, uncontrolled incineration of WES in the open could be harmful because electrical sockets are produced from melamine or urea formaldehyde.

Waste polymer reduction technology is an emerging area in Metallurgy where carbonaceous materials generated from waste polymers are used in place of or in combination with other carbonaceous materials as reductants for metal oxides reduction. For countries like Ghana where commercial quantities of iron ores are available, but without the relevant source of carbonaceous materials, waste polymers offer a readily available alternative to high grade metallurgical coke as reductant for iron making. In the metallurgical field, the use of postconsumer plastics as reductants or as a source of energy is currently gaining the attention of various researchers (Matsuda et al., 2006; Nishioka et al., 2007; Matsuda et al., 2008; Ueki et al., 2008; Dankwah et al., 2011; Kongkarat et al., 2011; Murakami et al., 2009; Murakami and Kasai, 2011; Dankwah et al., 2012; Dankwah et al., 2013; Dankwah and Koshy, 2014; Dankwah et al., 2015a; Dankwah et al., 2015b). However, most of the existing research in this area involves the use of thermoplastic polymers and or their blends with metallurgical coke, graphite, or biomass as reductants for the production of metallic iron from reagent grade iron oxides or electric arc furnace (EAF) slags containing iron oxide. For thermosetting plastics, Dankwah et al., 2012, Mansuri et al., 2013, Rajarao et al., 2014a, Rajarao et al., 2014b, Nath et al., 2012, Dhunna et al., 2014 and Dankwah and Baawuah, 2015 have used endof-life rubber tyres, waste compact discs, end-oflife melamine and waste bakelite as reductants or for carbon dissolution studies. Rajarao et al., (2014b) for instance studied the structural changes in the chars produced during the rapid pyrolysis of waste compact discs (CDs) in the temperature range 550-1550 ${ }^{\circ} \mathrm{C}$. They observed that the porosity and $\mathrm{C} / \mathrm{O}$ ratios of the chars increased with an increase in the pyrolysis temperature up to 850 ${ }^{\circ} \mathrm{C}$. Maximum porosity was achieved at $850{ }^{\circ} \mathrm{C}$ with char surface area of $334 \mathrm{~m}^{2} / \mathrm{g}$. Using the chars produced at $1550{ }^{\circ} \mathrm{C}$ as reductants, they were able to achieve about $90 \%$ iron oxide reduction.

Little or no information exists in the literature on the use of these waste polymers as reductants for the production of metallic iron from naturally occurring iron ores. Besides, the use of WES as reductants for metal production is not well studied.

The Agbaja iron deposit is located in Kogi State, Nigeria and is believed to be the largest deposit in Nigeria with an estimated reserve of about 1.2 billion metric tonnes (Obot and Anyakwo, 2012; 
Uwadiale, 1991). It has long been abandoned owing to its very high phosphorus content, variously estimated as $0.76-2.13 \%$ (Anyakwo and Obot, 2011; Uwadiale, 1991).

Accordingly, in this work, the feasibility of using WES as reductant for the production of metallic iron from the Agbaja iron ore is investigated through the microwave approach.

\section{Resources and Methods Used}

\subsection{Materials}

A quantified amount of WES was collected from the surroundings of the University of Mines and Technology (UMaT), Tarkwa. These were broken into pieces and rinsed with water in a plastic container to remove most of its associated debris. The cleaned thermosets were thereafter air dried for two days. Charring was done under controlled temperature conditions to upgrade the carbon content by expelling the volatile components of the material. The residence time of the charring process was $45 \mathrm{~min}$ using a gas fired furnace. The charred thermoset was ground using a ball mill for 10 minutes. The ground thermoset was screened for 15 minutes at amplitude of 20 using standard sieve sizes of $106 \mu \mathrm{m}, 90 \mu \mathrm{m}, 75 \mu \mathrm{m}$ and $53 \mu \mathrm{m}$. Medium grade Agbaja iron ore (73.748 wt $\% \mathrm{Fe}_{2} \mathrm{O}_{3}$ ) was used as the source of iron oxide (Table 1). The morphology of the Agbaja iron ore was observed by Scanning Electron Microscopy (SEM). The pulverised samples were characterised by XRD using an EMPYREAN Diffractometer.

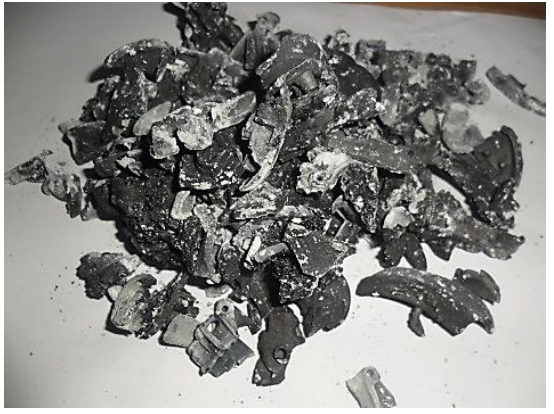

Fig. 1 Charred Thermosetting WES

Table 1: Chemical Composition (XRF) of Agbaja Iron Ore

\begin{tabular}{|l|c|}
\hline Component & Composition (wt.\%) \\
\hline $\mathrm{Fe}_{2} \mathrm{O}_{3}$ & 73.748 \\
\hline $\mathrm{SiO}_{2}$ & 3.820 \\
\hline $\mathrm{CaO}$ & 0.141 \\
\hline $\mathrm{Mn}_{3} \mathrm{O}_{4}$ & 0.469 \\
\hline $\mathrm{Al}_{2} \mathrm{O}_{3}$ & 5.433 \\
\hline $\mathrm{TiO}_{2}$ & 0.192 \\
\hline $\mathrm{Na}_{2} \mathrm{O}$ & 0.162 \\
\hline $\mathrm{MgO}$ & 0.748 \\
\hline $\mathrm{P}_{2} \mathrm{O}_{5}$ & 1.403 \\
\hline $\mathrm{LOI}$ & 13.678 \\
\hline TOTAL & 99.794 \\
\hline
\end{tabular}
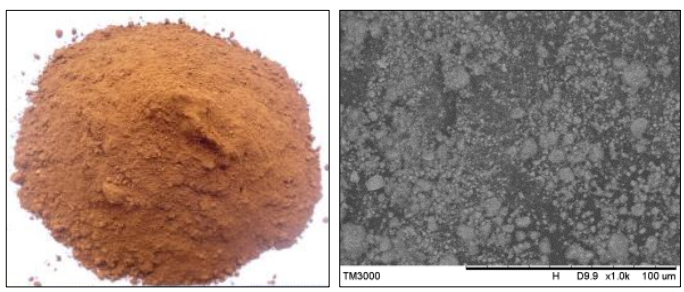

Fig. 2 a) Photo and b) SEM Photomicrograph of Pulverised Agbaja Iron Ore utilised for the Investigation

For pellet formation, about $14 \mathrm{~g}$ of iron ore and $6 \mathrm{~g}$ of the charred thermoset of the $-53 \mu \mathrm{m}$ were used. Weighing was done using an electronic balance and about $1 \mathrm{~g}$ of wheat flour was added to the mixture as a binding agent in all the pellets formation. Pellets were prepared into paste for moulding by adding water and stirring with plastic spoon to homogenise the mixtures. Pellets were cured and dried at atmospheric temperature for four days to remove physically held water in the pellets. The dry weights of the pellets were taken after curing using the electronic balance.

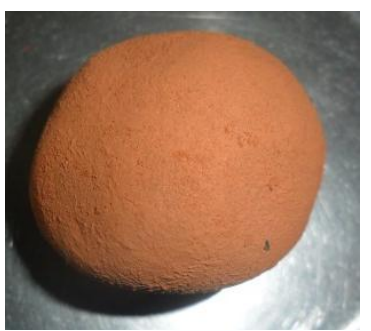

Fig. 3 Iron Ore-WES Composite Pellet

\subsection{Experimental Procedure}

The dried pellets were placed into a fireclay crucible and positioned at the central location of the microwave (Fig. 4) to ensure maximum concentration of the radiation emitted. After 40 minutes of firing, the crucible was taken out and quenched in air to stop any further reactions. The weights of the reduced iron pellets were recorded.

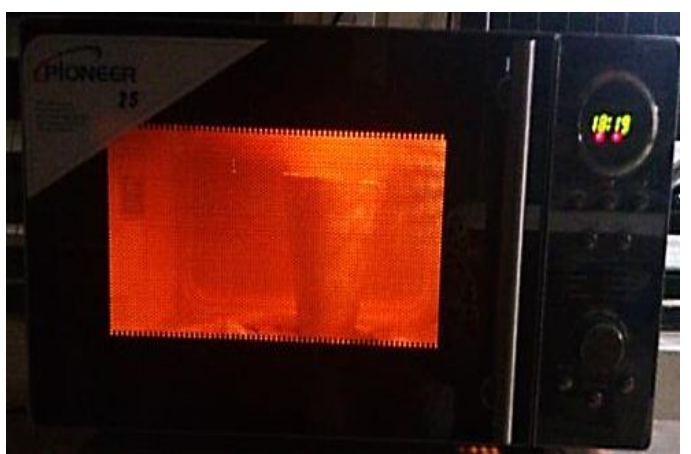

Fig. 4 Reduction Process in a Domestic Microwave Oven 


\section{Results and Discussion}

\subsection{Charred WES}

Fig. 5 shows SEM/EDS analysis of the solid product obtained after charring WES. Elemental analysis of region 1 shows a carbon content (of $67.4 \mathrm{wt} \%)$ reasonably above those of various forms of coals $(\sim 60 \mathrm{wt} \%)$ and polyethylene terephthalate (PET) ( 62.5 wt \%).
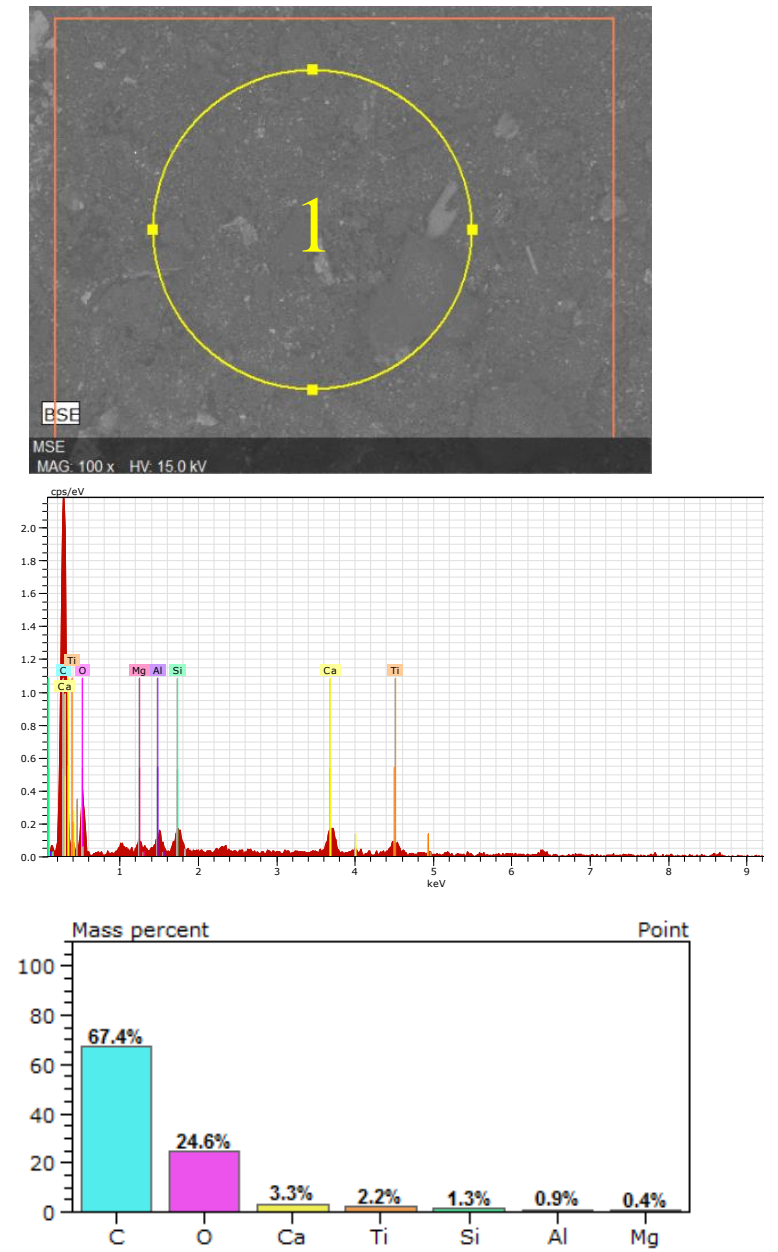

Fig. 5 SEM/EDX Analysis of Region 1 from Charred WES

It should therefore be possible to reduce iron oxide with charred WES. However, the efficiency of reduction will depend on the nature of ash obtained after the charring process.

The morphology of the ash obtained after the charring process is shown in the SEM of Fig 6 whilst the XRD is shown in Fig 7. The ash particles appear to be irregularly shaped as indicated in Fig 6 and consist of several crystalline peaks of calcite, quartz, corundum, halite, silicon and bornite.

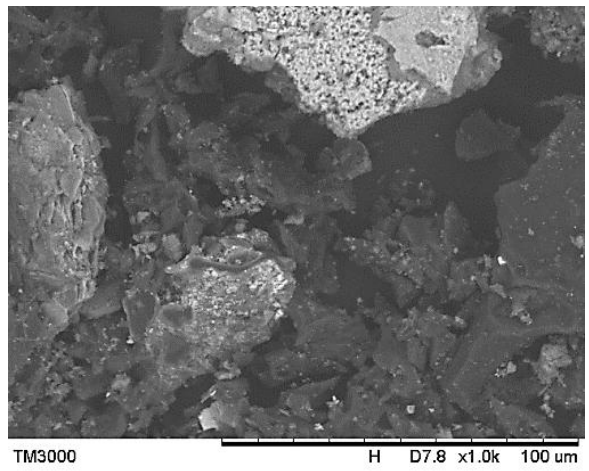

Fig. 6 SEM Photomicrograph of Ash obtained after Charring of WES

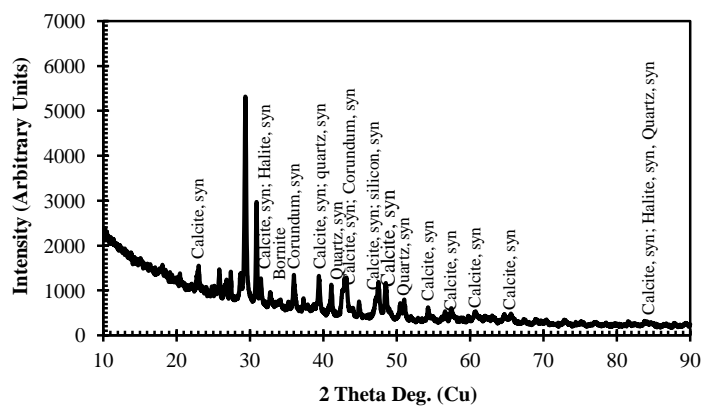

Fig. 7 XRD Patterns of Ash obtained after the Charring Process

\subsection{The Nature of the Agbaja Iron Ore}

The SEM/EDS analyses of the Agbaja iron ore before reduction are illustrated in Figs 8 and 9 for two regions 1 and 2. Region 1 shows an iron content of 55.12 wt \%, with Region 2 not very different at 53.32 wt \%. These values agree with the 54.17 wt \% Fe observed by Adedeji and Sale (1984) and are just around the minimum 55 wt \% $\mathrm{Fe}$ required for economic extraction of the apparently non self-fluxing Agbaja iron ore. The phosphorus content $\left(1.403\right.$ wt $\left.\% \mathrm{P}_{2} \mathrm{O}_{5}\right)$ of the ore was observed to be slightly lower than the $2.69 \mathrm{wt}$ $\% \mathrm{P}$ reported by Adedeji and Sale (1984) but within the $0.76-2.13 \%$ range estimated by previous researchers (Anyakwo and Obot, 2011; Uwadiale, 1991).

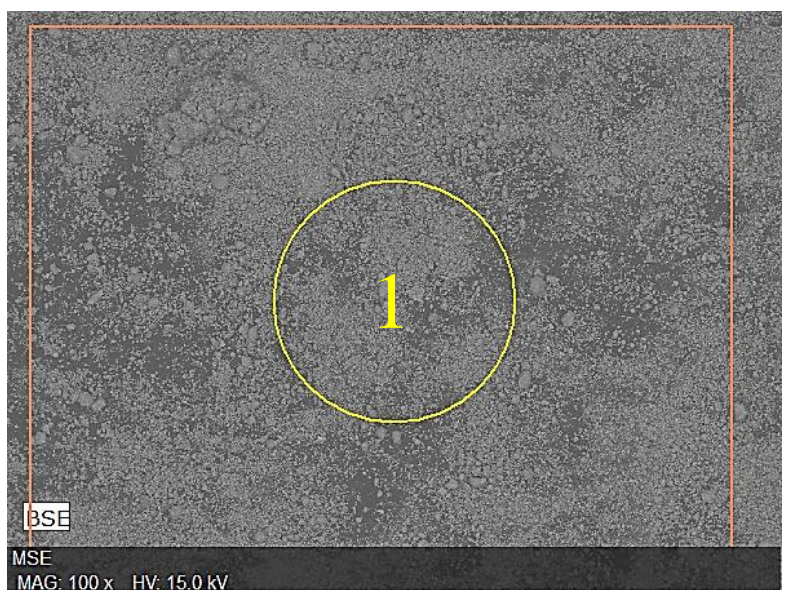




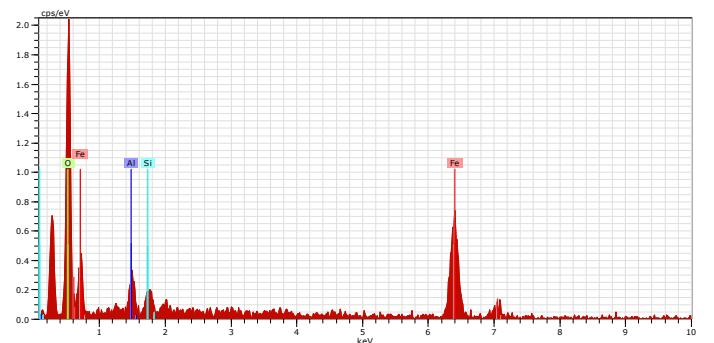

\begin{tabular}{lcc}
\hline Element (K-series) & Weight $\%$ & Atomic \% \\
\hline $\mathrm{Fe}$ & 55.12 & 26.77 \\
$\mathrm{O}$ & 40.85 & 69.24 \\
$\mathrm{Al}$ & 2.54 & 2.55 \\
$\mathrm{Si}$ & 1.49 & 1.44 \\
$\mathrm{SUM}$ & 100 & 100 \\
\hline
\end{tabular}

Fig. 8 SEM/EDS Analysis of Agbaja Iron Ore (Region 1)
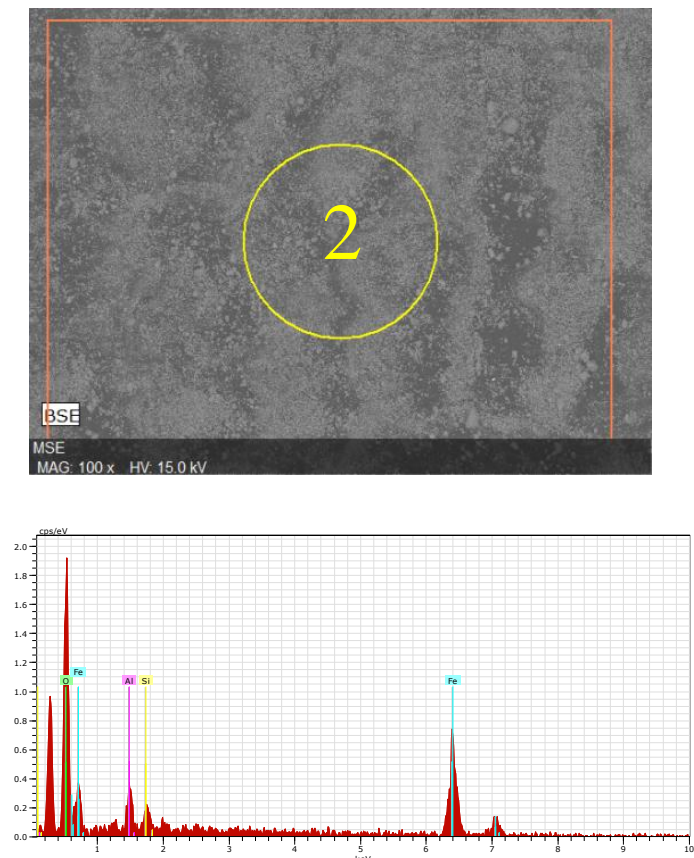

\begin{tabular}{lcc}
\hline Element (K-series) & Weight $\%$ & Atomic $\%$ \\
\hline $\mathrm{Fe}$ & 53.32 & 25.33 \\
$\mathrm{O}$ & 42.69 & 70.80 \\
$\mathrm{Al}$ & 2.68 & 2.64 \\
$\mathrm{Si}$ & 1.31 & 1.24 \\
$\mathrm{SUM}$ & 100 & 100 \\
\hline
\end{tabular}

Fig. 9 SEM/EDS Analysis of Agbaja Iron Ore (Region 2)

The ore was also characterised by XRD. The diffraction patterns are shown in Fig 10. The diffraction patterns correspond to those of $\mathrm{Fe}_{2} \mathrm{O}_{3}$. The product obtained after the reduction in the microwave is shown in Fig. 11.

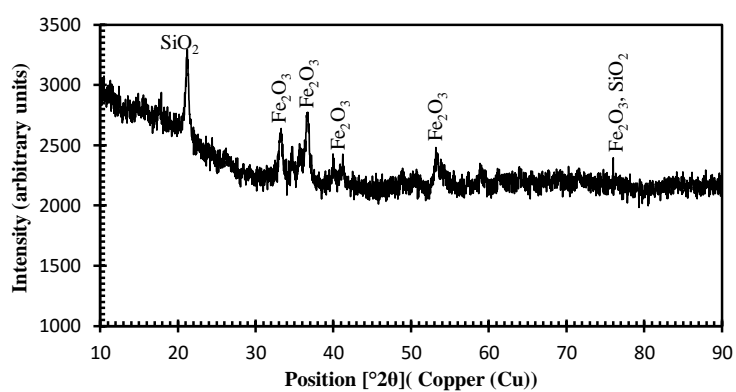

Fig. 10 XRD of Agbaja Iron Ore

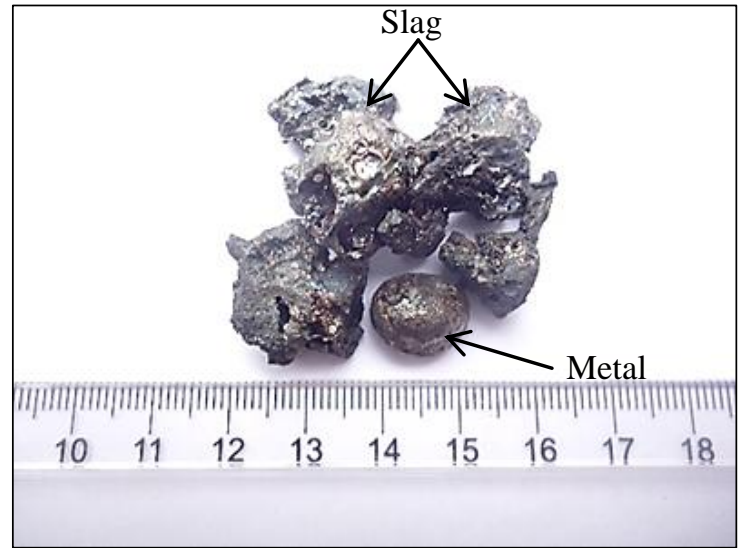

Fig. 11 Reduced Agbaja Ore along with Slag

The SEM of the reduced metal is shown in Fig 12 and SEM/EDS of three regions are shown in Figs 13, 14 and 15. The content of iron improved from an average of $54 \mathrm{wt} \%$ to $83.05,79.51$ and 84.67 in regions 1,2 and 3 , respectively. In these three regions, the $\mathrm{O} / \mathrm{Fe}$ atomic ratio $(0.70,0.87$ and 0.61 for regions 1,2 and 3, respectively) is significantly lower than 1.0, suggesting that reduction went far beyond the wustite stage.

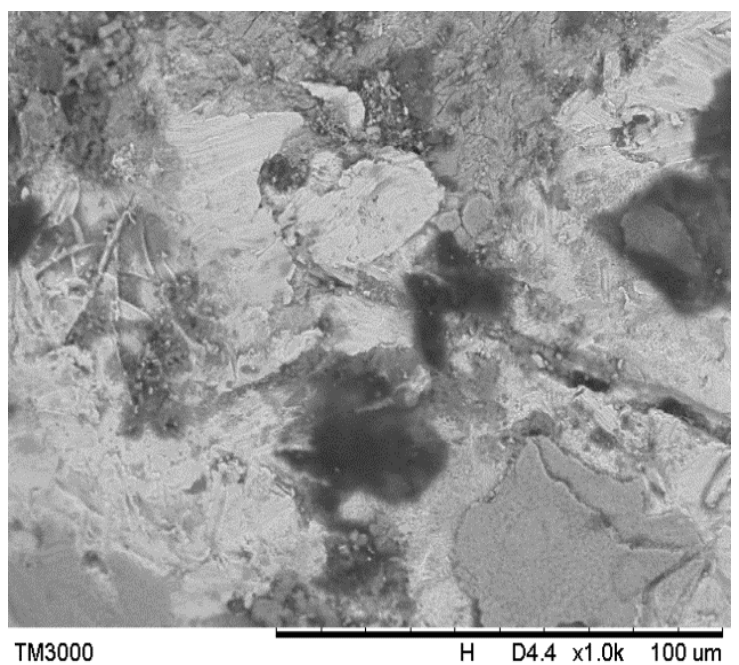

Fig. 12 SEM Photomicrograph of Reduced Agbaja Iron Ore 

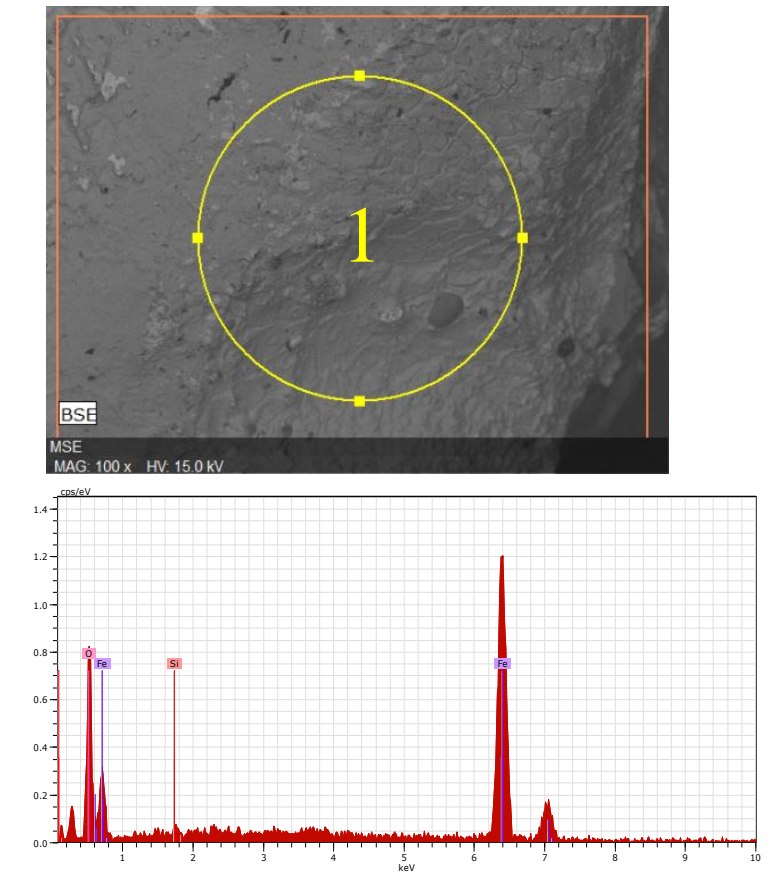

\begin{tabular}{lcc}
\hline Element (K-series) & Weight \% & Atomic \% \\
\hline $\mathrm{Fe}$ & 83.05 & 58.55 \\
$\mathrm{O}$ & 16.70 & 41.10 \\
$\mathrm{Si}$ & 0.25 & 0.35 \\
$\mathrm{SUM}$ & 100 & 100 \\
\hline
\end{tabular}

Fig. 13 SEM/EDS Analysis of Reduced Agbaja Iron Ore (Region 1)
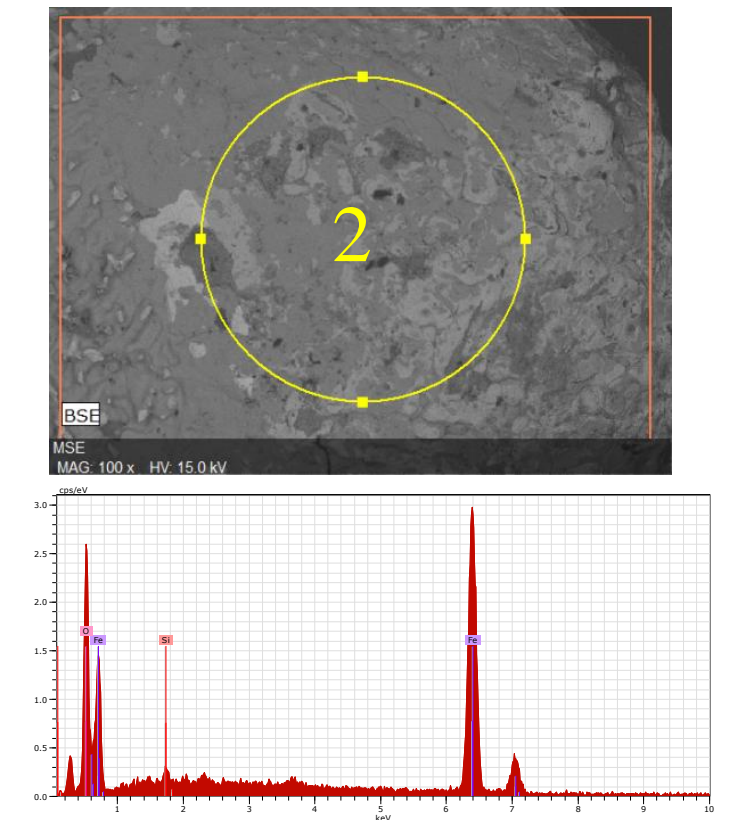

\begin{tabular}{lcc}
\hline \multicolumn{1}{c}{ Element (K-series) } & Weight $\%$ & Atomic \% \\
\hline $\mathrm{Fe}$ & 79.51 & 52.97 \\
$\mathrm{O}$ & 19.88 & 46.22 \\
$\mathrm{Si}$ & 0.61 & 0.81 \\
$\mathrm{SUM}$ & 100 & 100 \\
\hline
\end{tabular}

Fig. 14 SEM/EDS Analysis of Reduced Agbaja Iron Ore (Region 2)
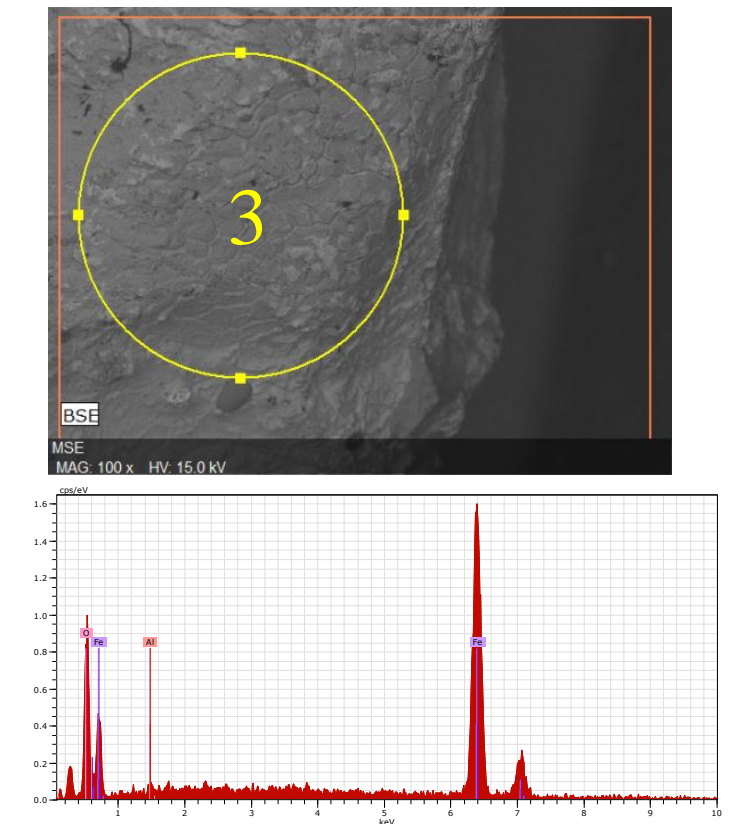

\begin{tabular}{lcc}
\hline Element (K-series) & Weight \% & Atomic \% \\
\hline $\mathrm{Fe}$ & 84.67 & 61.54 \\
$\mathrm{O}$ & 14.90 & 37.81 \\
$\mathrm{Si}$ & 0.43 & 0.65 \\
$\mathrm{SUM}$ & 100 & 100 \\
\hline
\end{tabular}

Fig. 15 SEM/EDS Analysis of Reduced Agbaja Iron Ore (Region 3)

The reduced metal was also characterised by XRD and the result is shown in Fig 16. Three sharp and distinct peaks corresponding to metallic iron occur at $2 \theta$ degree values of approximately 45,65 and 82.3. All other peaks corresponding to $\mathrm{Fe}_{2} \mathrm{O}_{3}$ in the original ore disappear completely. At this stage, the metal does not show any traces of phosphorus.

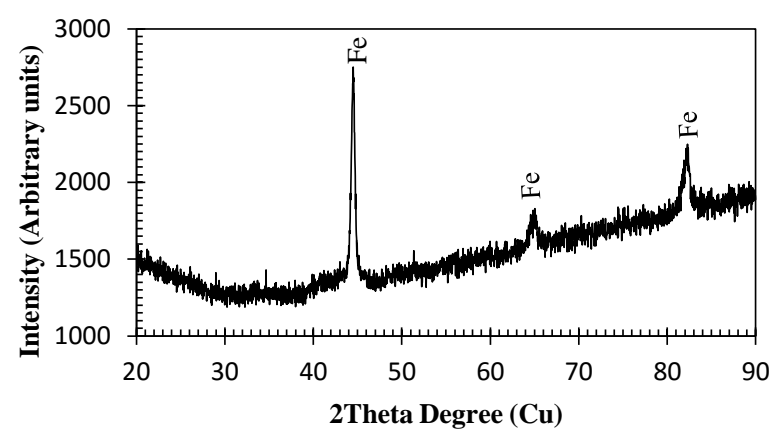

Fig. 16 XRD of Reduced Mass showing Peaks of Metallic Iron

\subsection{Extent of Reduction of Agbaja Iron Ore by WES}

The extent of reduction of the ore by WES was measured for five different experiments. The results are shown in Table 2. 
Table 2 Observed Extent of Reduction for various Experiments

\begin{tabular}{lcccc}
\hline $\begin{array}{l}\text { Expt. } \\
\text { No. }\end{array}$ & $\begin{array}{c}\text { Initial Mass } \\
\text { of Pellet }(\mathrm{g})\end{array}$ & $\begin{array}{c}\text { Final Mass } \\
\text { of Pellet }(\mathrm{g})\end{array}$ & $\begin{array}{c}\text { \% Wt. } \\
\text { Loss }\end{array}$ & $\begin{array}{c}\text { Extent of } \\
\text { Reduction } \\
(\%)\end{array}$ \\
\hline 1 & 18.71 & 10.03 & 46.39 & 84.64 \\
2 & 20.51 & 11.42 & 44.32 & 80.86 \\
3 & 19.87 & 10.42 & 47.56 & 86.77 \\
4 & 20.09 & 11.08 & 44.85 & 81.82 \\
5 & 21.93 & 12.09 & 44.87 & 81.86 \\
\hline
\end{tabular}

The average extent of reduction is about $83.2 \%$, which agrees with the average Fe content of 82.4 wt $\%$ for the SEM/EDS analyses for regions 1,2 and 3. Charred WES can therefore perform satisfactorily as reductant.

\section{Conclusions}

The reduction of the Agbaja iron ore has been investigated using carbonaceous material prepared from waste electrical sockets. Major findings of the investigation are:

(i) Waste electrical sockets (WES) are a potential source of carbonaceous materials for iron oxide reduction

(ii) The Agbaja iron ore can be successfully reduced using carbonaceous materials generated from WES.

(iii) Extent of reduction in excess of over $80 \%$ was observed.

\section{Acknowledgements}

Part of the analyses for the investigation was conducted at the School of Materials Science and Engineering and the Analytical Centre, School of Chemical Science and Engineering, UNSW, Sydney, Australia. The authors are grateful to the various authorising bodies for the assistance received.

\section{References}

Adedeji, F. A. and Sale, F. R. (1984), "Characterisation and Reducibility of Itakpe and Agbaja (Nigerian) Iron Ores", Clay Minerals, Vol. 19, pp. 843-856.

Anyakwo, C. N. and Obot, O. W. (2011), "Phosphorus Degradation Capability of Aspergillus Terreus on Nigeria's Agbaja Iron Ore", Journal of Minerals and Materials Characterisation and Engineering, Vol. 10, No. 12, pp. 1189-1196.

Dankwah, J. R., Koshy, P., Saha-Chaudhury, N. M., O'Kane, P., Skidmore, C., Knights, D. and Sahajwalla, V. (2011), "Reduction of $\mathrm{FeO}$ in EAF Steelmaking Slag by Blends of
Metallurgical Coke and Waste Plastics", ISIJ International, Vol. 51, No. 3, pp. 498-507.

Dankwah, J. R., Koshy, P., O'Kane, P. and Sahajwalla, V. (2012), "Reduction of $\mathrm{FeO}$ in EAF Steelmaking Slag by Blends of Metallurgical Coke and End-of-Life Tyres", Steel Research International, Vol. 83, No.8, pp. 766-774.

Dankwah, J.R., Koshy P. and Sahajwalla, V.H. (2013), "Reduction of FeO in EAF Steelmaking Slag by Blends of Metallurgical Coke and Endof-Life Polyethylene Terephthalate", Ironmaking and Steelmaking, Vol. 41, No. 6, pp. 401-409.

Dankwah, J.R., and Koshy, P. (2014), "Reduction of $\mathrm{FeO}$ in EAF Steelmaking Slag by Blends of Metallurgical Coke and Waste Polypropylene". High Temperature Materials and Processes, Vol. 33, No. 2, pp. 107-114.

Dankwah, J. R. and Baawuah, E. (2015), "Recycling Waste Bakelite as a Carbon Resource in Ironmaking", International Journal of Scientific and Technology Research (IJSTR), Vol. 4, Issue 2, pp. 257-261.

Dankwah, J. R., Fosu, A.Y., Fosu, N. and Koshy, P., (2015), "Carbothermal Upgrading of the Awaso Bauxite Ore using Waste Pure Water Sachets as Reductant", Ghana Mining Journal, Vol. 15, No. 1, pp. 64-72.

Dankwah, J. R., Amoah, T., Dankwah, J. and Fosu, A. Y., (2015), "Recycling Mixed Plastics Waste as Reductant in Ironmaking", Ghana Mining Journal, Vol. 15, No. 2, pp. 73-80.

Dhunna, R., Khanna, R., Mansuri, I. and Sahajwalla, V., (2014), "Recycling Waste Bakelite as an Alternative Carbon Resource for Ironmaking", ISIJ International, Vol. 54, No. 3, pp. 613-619.

Kongkarat, S., Khanna, R., Koshy, P., O’Kane, P., and Sahajwalla, V. (2011), "Use of Waste Bakelite as a Raw Material Resource for Recarburization in Steelmaking Processes" Steel Research International, Vol. 82(10), pp. 1228-1239.

Mansuri, I. A., Khanna, R., Rajarao, R. and Sahajwalla, V., (2013), "Recycling Waste CDs as Carbon Resource: Dissolution of Carbon into Molten Iron at $1550{ }^{\circ} \mathrm{C}$,' ISIJ International, Vol. 53, No. 12, pp. 2259-2265.

Matsuda, T., Takekawa, M., Hasegawa, M., Ikemura, Y., Wakimoto, K., Ariyama, T., and Iwase, M. (2006), "Utilization of Waste Wood for Production of Iron, Carbon Monoxide and Hydrogen without Generating Carbon Dioxide", Steel Res. Int., Vol. 77, pp. 774-784.

Matsuda, T., Hasegawa, M., Ikemura, A., Wakimoto, K., and Iwase, M. (2008), "Utilization of Waste Plastic for Production of Metallic Iron, Hydrogen and Carbon Monoxide without Generating Carbon Dioxide", ISIJ Int., Vol. 48, No. 9, pp. 1186-1196. 
Murakami, T., Akiyama, T. and Kasai, E., (2009), "Reduction Behaviour of Hematite Composite containing Polyethylene and Graphite with Different Structures with Increasing Temperature", ISIJ Int., 49(6), pp. 809-814

Murakami, T. and Kasai, E., (2011), "Reduction Mechanism of Iron Oxide-carbon Composite with Polyethylene at Lower Temperature", ISIJ Int., 51(1), pp. 9-13.

Nath, D. C. D., Mansuri, I. A., Zaharia, M., Saha Chaudhury, N. and Sahajwalla, V., (2012), "Recycling End-of-Life Melamine at $1600{ }^{\circ} \mathrm{C}$ for Carbon Dissolution into Liquid Iron", ISIJ International, Vol. 52, No. 5, pp. 922-927.

Nishioka, K., Taniguchi, T., Ueki, Y., Ohno, K., Maeda, T., and Shimizu, M. (2007), "Gasification and Reduction Behaviour of Plastic and Iron Ore Mixtures by Microwave Heating”, ISIJ Int., Vol. 47, No. 4, pp. 602-607.

Obot, O. W. and Anyakwo, C. N. (2012), "Removal of Phosphorus from Nigeria's Agbaja Iron Ore through the Degradation Ability of Micrococcus Species", International Journal of Water Resources and Environmental Engineering, Vol. 44, No. 4, pp. 114-119.

Rajarao, R., Mansuri, I. A., Dhunna, R., Khanna, R. and Sahajwalla, V., (2014), "Characterisation of Gas Evolution and Char Structural Change during Pyrolysis of Waste CDs", Journal of Analytical and Applied Pyrolysis, Vol. 105, pp. 14-22.

Rajarao, R., Mansuri, I., Dhunna, R. and Sahajwalla, V., (2014), "Study of Structural Evolution of Chars during Rapid Pyrolysis of Waste CDs at Different Temperatures", Fuel, Vol. 134, pp. 17-25.

Ueki, Y., Ohno, K., Maeda, T., Nishioka, K. and Shimizu, M. (2008), "Reaction Behaviour during Heating Waste Plastic Materials and Iron Oxide Composites", ISIJ Int., Vol. 48, pp. 1670-1675.

Uwadiale, G. G. O. O. (1991), "Electrolytic Coagulation and Selective Flocculation of Agbaja Iron Ore", Journal of Mining Geology, Vol. 27, No. 1, pp. 77-85.

\section{Authors}

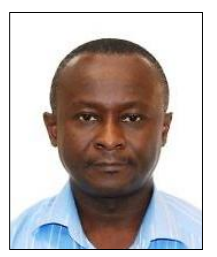

James R. Dankwah obtained his PhD from the School of Materials Science and Engineering, UNSW-Australia, MSc (Process Metallurgy) from the Norwegian University of Science and Technology and BSc (Metallurgical Engineering) from the Kwame Nkrumah University of Science and Technology, Kumasi, Ghana. His current research areas include iron and steelmaking, hightemperature metallurgical processes, utilisation of waste polymers in metal extraction processes and recycling agricultural waste into building blocks materials for affordable housing for rural folks.

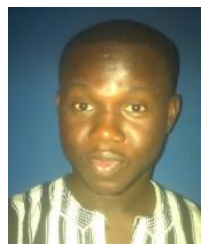

Emmanuel Abotar obtained his BSc degree in Minerals Engineering from the University of Mines and Technology, Tarkwa, Ghana. $\mathrm{He}$ worked on the utilisation of waste electrical sockets (WES) as reductants in ironmaking, with emphasis on the Agbaja iron ore from Nigeria.

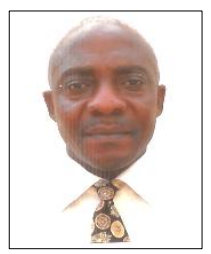

Joseph J. K. Gordon is a lecturer at the Minerals Engineering Department, UMaT, Tarkwa, Ghana. He obtained his BSc and MPhil degree in Metallurgical Engineering from the Kwame Nkrumah University of Science and Technology, Kumasi. His current research areas include Biotechnology, Mineral Processing and Extractive Metallurgy.

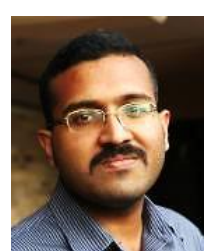

Pramod Koshy completed his Ph.D. from the School of Materials Science and Engineering, UNSW- Australia, Master of Technology, Materials Science and Technology, NIT-Calicut, India and Bachelor of Technology, Mechanical Engineering, University of Kerala, India. He is currently a Senior Research Associate at the School of Materials Science and Engineering, UNSW, Australia. His main areas of research include photocatalytic materials, high-temperature metal/ceramic interfaces, and utilisation of waste materials. 